\title{
Improving awareness of preconception health among adolescents: experience of a school-based intervention in Lebanon
}

\author{
Lama Charafeddine ${ }^{1,5}$, Rym El Rafei ${ }^{1,5}$, Sophie Azizi ${ }^{1}$, Durriyah Sinno ${ }^{5}$, Kawthar Alamiddine ${ }^{1,5}$, \\ Christopher P Howson ${ }^{3}$, Salimah R Walani ${ }^{3}$, Walid Ammar ${ }^{4}$, Anwar Nassar ${ }^{1,2}$ and Khalid Yunis ${ }^{1,5^{*}}$
}

\begin{abstract}
Background: Maternal behavior before and after conception affects maternal and child health. Limited awareness of adolescents in preconception health may be addressed through school education. The aim of this intervention is to assess preconception health awareness among adolescents in Lebanese high schools and to test the effectiveness of a one-time educational session in improving preconception knowledge.

Methods: The intervention consisted of a 30-minute educational session about good practices in preconception health, developed by the National Collaborative Perinatal Neonatal Network's (NCPNN) research team. A convenience sample of high school Lebanese students in grades 10 to 12 , aged 14 to 26 years old, from 70 private and public schools in all six Lebanese provinces, participated in the intervention in 2011 and 2012. A multiple-choice questionnaire administered prior to and 2 months after the session was used to assess knowledge improvement among the students.
\end{abstract}

Results: A total of 7,290 students were enrolled. After the session, mean scores of correct answers increased from 4.36 to 6.42 out of 10 , representing a $47.2 \%$ improvement $(p<0.001$ ). The percent of correct answers increased for all the questions regarding health practices $(p<0.001)$. The greatest improvement was observed for questions about Trisomy 21 , folic acid intake and toxoplasmosis with percentages improvement of $96 \%, 172 \%$ and $83 \%$ respectively. Being female or in private school was a significant predictor of higher scores in both pre-test and post-test $(p<0.001)$.

Conclusions: Awareness campaigns in schools increased the preconception health knowledge among high school students. We recommend expanding the scope of this intervention into universities in Lebanon.

Keywords: Preconception, Adolescents, Awareness campaign, Health education program, Health information

\section{Background}

Current scientific evidence indicates that, improving a woman's health before pregnancy (preconception health and health care) maximizes the potential for a healthy pregnancy outcome for both mother and infant [1]. Many women enter pregnancy in poor health with untreated preexisting conditions or without awareness of healthy behaviors, such as taking a daily folic acid supplement, avoiding exposure to tobacco and other teratogenic agents

\footnotetext{
*Correspondence: kayunis@aub.edu.lb

${ }^{1}$ the National Collaborative Perinatal Neonatal Network, American University of Beirut Medical Center, Beirut, Lebanon

${ }^{5}$ Department of Pediatrics and Adolescent Medicine, American University of Beirut Medical Center, Beirut, Lebanon

Full list of author information is available at the end of the article
}

or updating their immunizations; all of which put them at risk for maternal and neonatal adverse outcomes [2-4]. In addition, millions of women remain at risk for unintended pregnancy and lack the knowledge or motivation for access to reproductive health services [5].

Preconception health care involves the provision of health care to women and men during their reproductive years [6] and offering evidence-based interventions to reduce adverse outcomes in future pregnancies [7,8]. Adolescence is a particularly important point in the reproductive, maternal, newborn and child health $(\mathrm{RMNCH})$ continuum to promote preconception health [9]. Educating young women about healthy lifestyles not only empowers them as individuals in their own right, but also it can result in 
healthier maternal and newborn outcomes should they become pregnant [10-12].

Evidence from Lebanon highlights a need for promoting preconception health awareness. In a national survey of married Lebanese women aged 18 to 45 years, Nasr et al. found that $40 \%$ of the participants had not heard about pre-pregnancy folic acid and its prevention of neural tube defects (NTD) [13]. Tamim et al. showed a low prevalence $(14 \%)$ of preconception folic acid intake among 5,280 Lebanese pregnant women [14].

National data from the recently established birth defects surveillance system showed that among the mothers of 170 newborns identified with NTD in one year, only $6.7 \%$ reported having taken folic acid prior to pregnancy (unpublished data).

In addition, the 2011 "Global Youth Tobacco Survey in Lebanon" reported that among 2,339 male and female youths surveyed, $59.2 \%$ had never smoked cigarettes or water-pipe (shisha) and 11.3\% currently smoke cigarettes; of those surveyed, 70\% were between 13 and 15 years of age [15]. Other growing problems during pregnancy are obesity and diabetes which are both associated with adverse maternal and neonatal outcomes [16,17]. In the Lebanese adolescent population, the prevalence of obesity was reported as $28 \%$ and $31.5 \%$ in 1997 and 2009 respectively [16]. Furthermore, reproductive outcomes are also linked to the father's health and lifestyle; [18] whereas fathers' smoking leads to fetal secondhand smoke exposure, hence increased risk of low birthweight and later, sudden infant death syndrome $[19,20]$. Thus, it is essential to target young men's awareness about preconception health and behaviors and encourage them to play a more supportive role prior to and during their partner's pregnancy [21].

Improving health knowledge, attitudes and behaviors of both young women and men is an essential step in promoting preconception health [6]. The school system represents a natural venue to reach adolescents. Indeed, college health education programs have been shown to improve preconception awareness among youth $[21,22]$.

The purpose of this paper is to present the experience of a preconception health education intervention conducted in high schools in Lebanon, and to demonstrate the impact of such a program in improving knowledge of benefits of preconception health.

\section{Methods}

\section{Study, design and setting}

This intervention was carried out in 70 public and private high schools in Lebanon over a 2-year period (2011 to 2012) by the National Collaborative Perinatal Neonatal Network (NCPNN) team in collaboration with the Lebanese Ministries of Education and Health. The NCPNN is a hospital-based network of health professionals across Lebanon whose goal is to improve maternal and neonatal health [23].

The intervention was implemented in all six Lebanese provinces: the Capital city, the central, southern, northern, eastern and east-southern provinces. It consisted of a 20-minute lecture session for students in grades 10 through 12. The session material, developed by experts from the NCPNN team, included 28 slides addressing conditions affecting reproductive outcomes. These conditions were: obesity and underweight; infectious diseases, in particular toxoplasmosis; chronic conditions such as diabetes and epilepsy, smoking, alcohol and recreational drug usage as well as certain medications. At each session, the importance of a healthy lifestyle, childhood immunizations and pre-pregnancy folic acid intake were stressed. Birth defects, preterm births and their increased risks associated with poor preconception health status were among the topics presented.

\section{Process and intervention}

Exemption approval was obtained from the Institutional Review Board of the American University of Beirut to conduct the intervention. Consent by the students was not needed as the knowledge questionnaires didn't include any identifiers and it was specified verbally to them that their participation to fill in the questionnaires was voluntary. Written approval from the Lebanese Ministry of Education was however obtained. A list of public schools was provided by the Lebanese Ministry of Education accordingly. An enforcement letter for participation addressed to the schools' administrators and teachers was sent by the Lebanese Ministry of Education to each public school. Following permission from the schools' administrators of both public and private schools, the implementation visits were scheduled. Verbal informed consent also was taken from the students upon distribution of the anonymous pre-test questionnaire. Refusal to fill in the pre-test questionnaire did not hamper the students from attending the lecture.

The intervention was completed in 41 public schools chosen randomly from the list provided from the Lebanese Ministry of Education to cover all provinces. Following the convenience sampling, 49 private schools from all provinces were approached; 29 agreed to participate.

Before initiating the intervention, the NCPNN lecturers (pediatricians, obstetricians, nurse leaders) discussed the presentation's content and reached an agreement regarding the uniformity of leading each session. Prior to each session, the project leader reviewed again the presentation with the lecturer for that session. On average, two schools were visited per day over a 3-month period. Students from grades 10 to 12 were selected to attend the lecture. 
To assess students' baseline knowledge, a self-administrated questionnaire was developed in English and Arabic and was given to each participant before the session (Additional file 1). The questionnaire, which took about 10 minutes to complete, had two sections. The first section asked about socio-demographic characteristics; the second section contained ten multiple choice questions about the preconception health topics of discussion. Students were informed of their right to decline to answer individual questions; they were reassured that the questionnaire would be anonymous and that their performance would neither affect their grades nor cause any penalty for wrong answers.

After administering the questionnaire, the NCPNN lecturer gave the presentation in Arabic or English depending on the students' preference. The session continued with an informal open discussion in which students were given the opportunity to ask further questions. Two months after the intervention, the same questionnaire was mailed to each school requesting to have it completed by the same students who participated in the educational sessions and returned by prepaid mail.

\section{Statistical analysis}

Data were analyzed using Statistical Program for Social Science version-20 (SPSS). A calculated variable "total score of correct answers" was created to measure each student's knowledge level on a scale from 1 to 10 , based on the responses to the 10 knowledge questions. Correct answers were scored as " 1 " and incorrect or "I do not know" answers were scored as "0". Means and standard deviations were calculated for continuous variables while the categorical variables were analyzed in frequencies and percentages. Chi-square test was used to compare categorical variables and independent sample t-test to compare total scores. Multiple linear regression was used to assess the independent relationship of the intervention and all the socio-demographic characteristics on all scores (pre and post). Statistical significance was set at an alpha of 0.05 .

\section{Results}

\section{Study population}

The health education intervention was conducted in 70 schools (41 public and 29 private) reaching a total of 7,290 students. Overall, $79.4 \%$ of those who took the pre-test returned the post-intervention questionnaires 2 months after their session.

Of the total participants at baseline, $63.6 \%$ were from public schools, $57.1 \%$ in grade $11,75.0 \%$ were aged between 14 and 18 years, $18.9 \%$ were boys, and $26.3 \%$ were engaged to be married in the year following the intervention. Information about the students' parental profession showed that the majority of mothers were housewives, and only $4.1 \%$ of the fathers were working in the medical or paramedical field (Table 1).

\section{Knowledge assessment}

The participants' mean knowledge score at baseline was 4.36 out of 10 . Two months after the session, mean knowledge scores in the post-test increased to $6.42(p<0.001)$, representing $47.2 \%$ improvement. The percentage of students who answered correctly improved significantly for all the questions $(p<0.001)$. Answers to questions regarding risk of Trisomy 21, folic acid intake and toxoplasmosis showed the highest improvement percentages of 96\%, $172 \%$ and $83 \%$ respectively (Table 2 ).

The number of correct answers was compared among male and female students in mixed classes only. The number of female students who answered correctly in the post-test was significantly higher than the males in all the topics $(p<0.012)$ except for "folic acid intake before pregnancy" $(p=0.10)$ and "alcohol, smoking and illicit drugs" $(p=0.45)$.

When answers were analyzed by grade level, scores at baseline were slightly different among grades 10, 11 and 12 with the highest score reached among grade 12 students (4.83 over 10$)$. However, following the educational session, grade 10 students showed the highest knowledge improvement rate of $64.8 \%$ as compared to the other grades: $45.8 \%$ for grade 11 and $39.9 \%$ for grade 12 . The number of correct responses in the post-test was significantly different among all three grades and for all questions $(p<0.02)$ except for the ones on toxoplasmosis $(p=0.44)$, medications \& pregnancy $(p=0.23)$ and alcohol, smoking and illicit drugs $(p=0.13)$.

\section{Factors associated with higher test scores}

Table 3 shows the relationship between the scores before and after the intervention and the socio-demographic characteristics at the bivariate level. The mean scores in both pre- and post-tests were statistically related to gender, age group, provinces, school type and grade level $(p<0.05)$.

The independent factors predicting higher knowledge scores were: the intervention itself $(\beta=1.944,95 \% \mathrm{CI}$ 1.834 - 2.054); female gender $(\beta=0.421,95 \%$ CI 0.309 0.532 ); the location by province (central province: $\beta=$ $0.356,95 \%$ CI 0.182 - 0.530, southern province: $\beta=1.009$, 95\% CI 0.844 - 1.173, northern province: $\beta=0.566,95 \%$ CI $0.362-0.769$, eastern province: $\beta=0.783,95 \%$ CI 0.475 - 1.090, east-south province: $\beta=1.128,95 \% \mathrm{CI}$ 0.918 - 1.337); school type $(\beta=0.286,95 \%$ CI $0.147-0.425)$; and grade level (Grade11: $\beta=0.221,95 \%$ CI $-0.017-0.458$, Grade 12: $\beta=0.506,95 \%$ CI $0.261-0.751$, technical baccalaureate 3 (BT3): $\beta=0.931,95 \%$ CI $0.406-1.455)$. Having participated in the intervention, being a female, going to a private school or living in the southern provinces were 
Table 1 Socio-demographic characteristics of the students based on pre-test analysis*

\begin{tabular}{ll}
\hline General characteristics of the students & $\mathbf{N}=\mathbf{7 , 2 9 0}(\%)$ \\
\hline Gender & \\
$\quad$ Male & $1,346(18.9 \%)$ \\
$\quad$ Female & $5,791(81.1 \%)$ \\
Age & \\
$\quad<18$ years & $5,198(75.0 \%)$ \\
$\quad \geq 18$ years & $1,734(25.0 \%)$ \\
$\quad$ Mean \pm SD & $16.94 \pm 0.99$ \\
Provinces &
\end{tabular}

Capital city (Beirut)

Central Province (Mount Lebanon)

Southern Province (South Lebanon)

Northern Province (North Lebanon)

Eastern Province (Bekaa valley)

East southern province (Nabatieh)

\section{School type}

Public

Private

Study class

Grade 10

Grade 11

Grade 12

Technical baccalaureate 3 (BT3)

Parents with chronic condition

No

Yes

Don't know

Father's profession

Not working

Technical \& other

Non-medical

Medical \& paramedical

Mother's profession

Housewife

Technical \& other

Non-medical

Medical \& paramedical

The following characteristics were from the $2^{\text {nd }}$ year of the intervention only

\section{Marital status}

Single

Engaged

Father's education

Primary or less

Middle school
$1,323(18.1 \%)$

$1,600(21.9 \%)$

$1,916(26.3 \%)$

$1,189(16.3 \%)$

$528(7.2 \%)$

$734(10.1 \%)$

$4,639(63.6 \%)$

$2,651(36.4 \%)$

$397(5.7 \%)$

$2,561(36.6 \%)$

$41(0.6 \%)$

$5,091(75.1 \%)$

$1,470(21.7 \%)$

$218(3.2 \%)$

$158(2.6 \%)$

$2,382(39.2 \%)$

$3,288(54.1 \%)$

$246(4.1 \%)$

$4,673(78.1 \%)$

$235(3.9 \%)$

924(15.4\%)

$149(2.5 \%)$

$\mathrm{N}=3697,(\%)$

$2,576(73.7 \%)$

$920(26.3 \%)$

$456(13.2 \%)$

$964(27.9 \%)$
$3,996(57.1 \%)$
Table 1 Socio-demographic characteristics of the students based on pre-test analysis* (Continued)

\begin{tabular}{lc}
\hline Secondary/high school & $966(28.0 \%)$ \\
University & $1,070(31.0 \%)$ \\
Mother's education & \\
Primary or less & $341(9.8 \%)$ \\
Middle school & $965(27.7 \%)$ \\
Secondary/high school & $1,203(34.5 \%)$ \\
University & $980(28.1 \%)$ \\
\hline${ }^{*}$ Missing not shown.
\end{tabular}

independently associated with a higher score of correct answers $(\mathrm{p}<0.001)$ (Table 4).

\section{Discussion}

This study describes a successful implementation of a school-based intervention to increase Lebanese adolescents' knowledge and importance about preconception health practices. Students in the higher grade levels had higher baseline knowledge compared to those in lower grades who demonstrated greater improvement from baseline. Being female or enrolled in a private school was a significant predictor of higher scores at baseline as well as after the intervention.

Intervention to educate adolescents about preconception health is novel in our region because of the sensitivity of the topic. Preconception health education is not part of the official school curriculum, and preconception issues are not discussed between parents and adolescents [24]. Pediatricians in Lebanon are less likely to address prevention and health education routinely in their practice (personal observation).

A similar intervention in rural India demonstrated an increase in adolescents' knowledge after giving lectures on reproductive health; [25] Delgado showed moderate improvement in knowledge after preconception health courses at the University of Miami [21,22].

In the present study, adolescents' knowledge about the benefits of preconception health and in particular to the importance of folic acid intake prior to conception was particularly poor, and this was true for all students regardless of their age, gender or grade level. These results are in accordance with Delgado who found that only $32 \%$ of college students were aware of the importance of folic acid intake in the early fetal development [21]. Similarly, $36 \%$ of women in the undergraduate psychology program in Virginia Commonwealth University had not heard about folic acid [26].

Among the high school students who participated in our intervention, $26 \%$ were engaged to be married and were unlikely to be taking folic acid since there was a large gap in knowledge regarding the importance of folic 
Table 2 Knowledge assessment score before and after the intervention*

Preconception health components Pre-test $\mathrm{N},(\%) \mathrm{N}=7,290$

Post-test $\mathrm{N},(\%) \mathrm{N}=5,786$

$p$-value

Seeking medical advice

True

False

Don't know

Trisomy 21

True

False

Don't know

$$
\begin{gathered}
4,646(65.2 \%) \\
2,119(29.7 \%) \\
361(5.1 \%)
\end{gathered}
$$

1,785 (24.8\%)

4,058 (56.3\%)

1,364 (18.9\%)

Pre-pregnancy folic acid

True

False

Don't know

\section{Diabetes}

True

False

Don't know

\section{Epilepsy}

True

False

Don't know

\section{Toxoplasmosis}

True

False

Don't know

Medication \& pregnancy

True

False

Don't know

\section{Obesity}

True

False

Don't know

Alcohol, smoking and illicit drugs

$\begin{array}{lc}\text { True } & 5,223(72.3 \%) \\ \text { False } & 1,385(19.2 \%) \\ \text { Don't know } & 616(8.5 \%) \\ \text { Vaccination } & \\ \text { True } & 2,399(66.6 \%) \\ \text { False } & 329(9.1 \%) \\ \text { Don't know } & 873(24.2 \%)\end{array}$

Total score $($ mean \pm SD)

$1,529(21.4 \%)$

$2,751(38.6 \%)$

$2,853(40.0 \%)$

$3,836(53.5 \%)$

$353(4.9 \%)$

$2,977(41.5 \%)$

$2,851(40.3 \%)$

$1,040(14.7 \%)$

$3,192(45.1 \%)$

$3,130(43.4 \%)$

2,000 (27.8\%)

$2,074(28.8 \%)$

3,864 (54.5\%)

906 (12.8\%)

$2,319(32.7 \%)$

2,519 (35.1\%)

$4.36 \pm 1.8$

$$
\begin{gathered}
4,243(75.3 \%) \\
1,262(22.4 \%) \\
132(2.3 \%)
\end{gathered}
$$

2,777 (48.8\%)

2,416 (42.4\%)

502 (8.8\%)

$3,240(58.3 \%)$

1,406 (25.3\%)

$<0.001$

908 (16.3\%)

3,963 (69.9\%)

736 (13.0\%)

$<0.001$

968 (17.1\%)

$3,265(58.3 \%)$

1,103 (19.7\%)

$<0.001$

1,235 (22.0\%)

4,484 (79.4\%)

667 (11.8\%)

$<0.001$

497 (8.8\%)

$4,420(79.0 \%)$

491 (8.8\%)

$<0.001$

$685(12.2 \%)$

3,388 (59.6\%)

$1,728(30.4 \%)$

$<0.001$

572 (10.1\%)

$4,804(84.0 \%)$

$652(11.4 \%)$

$<0.001$

261 (4.6\%)

$2,410(86.1 \%)$

128 (4.6\%)

$<0.001$

$6.42+2.1$

$<0.001$ 
Table 3 Factors associated with knowledge scores for "Pre- and post-test" questionnaires

\begin{tabular}{|c|c|c|c|c|}
\hline Socio-demographic characteristics & $\frac{\text { Pre-test }}{\text { Mean } \pm \text { SD }}$ & $p$-value & $\frac{\text { Post-test }}{\text { Mean } \pm \text { SD }}$ & $p$-value \\
\hline \multicolumn{5}{|l|}{ Gender } \\
\hline Male & $4.21 \pm 1.92$ & \multirow{2}{*}{$<0.001$} & $5.91 \pm 2.37$ & \multirow{2}{*}{$<0.001$} \\
\hline Female & $4.41 \pm 1.79$ & & $6.54 \pm 2.06$ & \\
\hline \multicolumn{5}{|l|}{ Age } \\
\hline$<18$ years & $4.35 \pm 1.82$ & \multirow{2}{*}{0.019} & $6.91 \pm 2.14$ & \multirow{2}{*}{$<0.001$} \\
\hline$\geq 18$ years & $4.47 \pm 1.77$ & & $6.61 \pm 2.12$ & \\
\hline \multicolumn{5}{|l|}{ Provinces } \\
\hline Capital city (Beirut) & $4.30 \pm 1.77$ & \multirow{6}{*}{$<0.001$} & $5.87 \pm 2.12$ & \multirow{6}{*}{$<0.001$} \\
\hline Central Province (Mount Lebanon) & $4.37 \pm 1.79$ & & $6.37 \pm 1.96$ & \\
\hline Southern Province (South Lebanon) & $4.57 \pm 1.79$ & & $6.71 \pm 1.98$ & \\
\hline Northern Province (North Lebanon) & $4.15 \pm 1.83$ & & $5.69 \pm 2.24$ & \\
\hline Eastern Province (Bekaa valley) & $4.31 \pm 1.75$ & & $7.05 \pm 2.12$ & \\
\hline East southern province (Nabatieh) & $4.33 \pm 1.97$ & & $7.44 \pm 2.17$ & \\
\hline \multicolumn{5}{|l|}{ School type } \\
\hline Public & $4.33 \pm 1.80$ & \multirow{2}{*}{0.017} & $6.32 \pm 2.11$ & \multirow{2}{*}{$<0.001$} \\
\hline Private & $4.43 \pm 1.84$ & & $6.56 \pm 2.19$ & \\
\hline \multicolumn{5}{|l|}{ Grade level } \\
\hline Grade 10 & $4.16 \pm 1.95$ & \multirow{4}{*}{$<0.001$} & $7.15 \pm 2.14$ & \multirow{4}{*}{$<0.001$} \\
\hline Grade 11 & $4.33 \pm 1.82$ & & $6.44 \pm 2.17$ & \\
\hline Grade 12 & $4.54 \pm 1.75$ & & $6.41 \pm 2.02$ & \\
\hline Technical baccalaureate 3 (BT3) & $4.34 \pm 2.11$ & & $6.66 \pm 2.19$ & \\
\hline \multicolumn{5}{|l|}{ Parents with chronic condition } \\
\hline No & $4.36 \pm 1.79$ & \multirow{3}{*}{$<0.001$} & $6.43 \pm 2.14$ & \multirow{3}{*}{$<0.001$} \\
\hline Yes & $4.52 \pm 1.83$ & & $6.56 \pm 2.06$ & \\
\hline Don't know & $3.79 \pm 1.94$ & & $5.16 \pm 2.42$ & \\
\hline \multicolumn{5}{|l|}{ Father's profession } \\
\hline Not working & $4.29 \pm 1.91$ & \multirow{4}{*}{0.404} & $6.51 \pm 2.30$ & \multirow{4}{*}{$<0.001$} \\
\hline Technical/other & $4.33 \pm 1.80$ & & $6.14 \pm 2.10$ & \\
\hline Non-medical & $4.41 \pm 1.81$ & & $6.57 \pm 2.13$ & \\
\hline Medical \& paramedical & $4.40 \pm 1.69$ & & $6.34 \pm 2.16$ & \\
\hline \multicolumn{5}{|l|}{ Mother's profession } \\
\hline Not working & $4.37 \pm 1.81$ & \multirow{4}{*}{0.139} & $6.55 \pm 2.10$ & \multirow{4}{*}{0.222} \\
\hline Technical/other & $4.40 \pm 1.73$ & & $6.30 \pm 1.92$ & \\
\hline Non-medical & $4.47 \pm 1.78$ & & $6.43 \pm 2.22$ & \\
\hline Medical \& paramedical & $4.64 \pm 1.75$ & & $6.64 \pm 1.97$ & \\
\hline
\end{tabular}

acid prior to pregnancy. Preconception folic acid intake represents a major public health challenge since universal fortification in Lebanon has not been implemented, yet the rate of neural tube defects (NTD) in Lebanon is estimated at 13.2 per 10,000 (unpublished data from the national birth defects registry/NCPNN/ May $1^{\text {st }} 2012-$ December $\left.31^{\text {st }} 2013\right)$ compared to 4.6 per 10,000 reported in the United States [27].
Before attending the educational session, a modest percent of students were knowledgeable about the fetalrelated risks of obesity (35.1\%) and diabetes (53.5\%). This finding is in agreement with another study where $65 \%$ of diabetic adolescents were unaware of preconception health and 34\% knew nothing about diabetes and pregnancy [28]. Knowing that the prevalence of obesity among children in Lebanon has increased significantly 


\begin{tabular}{|c|c|c|c|}
\hline & $B^{*}$ & $95.0 \% \mathrm{Cl}^{*}$ & $p$-value \\
\hline \multicolumn{4}{|l|}{ Intervention } \\
\hline Pre & 1.0 & Reference & \\
\hline Post & 1.944 & $1.834,2.054$ & $<0.001$ \\
\hline \multicolumn{4}{|l|}{ Gender } \\
\hline Male & 1.0 & Reference & \\
\hline Female & 0.421 & $0.309,0.532$ & $<0.001$ \\
\hline \multicolumn{4}{|l|}{ Provinces } \\
\hline Capital city (Beirut) & 1.0 & Reference & \\
\hline Central Province (Mount Lebanon) & 0.356 & $0.182,0.530$ & $<0.001$ \\
\hline Southern Province (South Lebanon) & 1.009 & $0.844,1.173$ & $<0.001$ \\
\hline Northern Province (North Lebanon) & 0.566 & $0.362,0.769$ & $<0.001$ \\
\hline Eastern Province (Bekaa valley) & 0.783 & $0.475,1.090$ & 0.001 \\
\hline East southern province (Nabatieh) & 1.128 & $0.918,1.337$ & $<0.001$ \\
\hline \multicolumn{4}{|l|}{ School type } \\
\hline Public & 1.0 & Reference & \\
\hline Private & 0.286 & $0.147,0.425$ & $<0.001$ \\
\hline \multicolumn{4}{|l|}{ Grade Level } \\
\hline Grade 10 & 1.0 & Reference & \\
\hline Grade 11 & 0.221 & $-0.017,0.458$ & 0.069 \\
\hline Grade 12 & 0.506 & $0.261,0.751$ & $<0.001$ \\
\hline Technical baccalaureate 3 (BT3) & 0.931 & $0.406,1.455$ & 0.001 \\
\hline
\end{tabular}

In the following table, only mixed classes is included in the analysis. *B: Regression coefficient, Cl: confidence interval.

over the past decade [16], it is important to increase adolescents' awareness about the implications of obesity on the health of mother and fetus during pregnancy.

After participating in this intervention, approximately $80 \%$ of the high school students showed improvement in their knowledge scores in contrast to $100 \%$ among college students receiving a semester-long class intervention [22]. This finding could be related either to the younger age of the high school students or to factors related to the mode of delivery of such interventions.

It is interesting to note that after the intervention, students in lower grades had better scores than those in higher grades. Whether this is related to the fact that younger adolescents may have paid more attention or were more interested in the topic is not clear.

Perhaps the most reassuring finding is that students had good baseline knowledge about the danger of substance abuse during pregnancy, namely alcohol, cigarette and shisha smoking, and illicit drugs. This contrasts with other findings in Lebanon, where the prevalence of smoking in women during pregnancy is 25 to $27 \%$ [29] and the reported smoking rate in Lebanese adolescents is 60\% [30]. However, recent aggressive campaigns against smoking
[31] have led to the signature of a law on tobacco control (law 174), banning smoking in public places [32,33]. Whether adolescents' smoking behavior will change after the institution of this law remains to be explored, since knowledge does not necessarily translate into change in behavior.

This study highlights the need for increasing health literacy among adolescents early on during their school years and for targeting not only female but also male adolescents who are potential future partners in any pregnancy. The study also demonstrates that adolescents of all socio-demographic backgrounds should be targeted.

Although this intervention resulted in improved knowledge, several limitations are to be acknowledged. Time constraints and limited resources prevented the participation of $33.8 \%$ of chosen public schools; misconceptions and reservations regarding sensitive issues related to sexuality among adolescents were the reasons for refusal of participation by almost half of the private schools contacted. Furthermore, the intervention was relatively lengthy and was conducted in large classrooms, which limited the discussion time. The anonymous nature of the questionnaire also precluded pairing the pre- and post-test results for individual comparisons.

Finally, since the ministry of education recommended initiating this intervention in "girls only" public schools, there were only $18.9 \%$ male participants; this affects the generalizability of the findings in terms of gender differences.

Despite these limitations, this school-based intervention proved to be successful in improving preconception health knowledge. Yet, reaching large populations of students in classroom settings is time consuming and can hinder more detailed discussions. Reaching large numbers of adolescents in more efficient and appealing ways should be explored. Use of current technologies (e.g., mobile phones) to disseminate preconception health information to adolescents may be may be more appealing to them than getting information from parents, relatives or teachers.

\section{Conclusions}

In summary, increasing knowledge and influencing behavioral change of young men and women is expected to improve the health of women before pregnancy and reduce non-life- threatening adverse outcomes (birth defects, low birthweight, prematurity). To this effect, using new approaches to include topics related to non-communicable diseases and reproductive health might prove to be influential; however, the feasibility, cultural acceptance and potential impact on knowledge and behaviors of this target population needs to be evaluated. 


\section{Additional file}

Additional file 1: Attached represents the pre and post knowledge assessment questionnaire used in this intervention.

\section{Abbreviations}

BT3: Technical Baccalaureate 3; Cl: Confidence Interval; NCPNN: National Collaborative Perinatal Neonatal Network; NTD: Neural Tube Defects; RMNCH: Reproductive Maternal, Newborn and Child Health; SPSS: Statistical Program for Social Science.

\section{Competing interests}

The authors declare that they have no competing interests.

\section{Authors' contribution}

SA, LC, RER, AN and KY are reporting on behalf of the National Collaborative Perinatal Neonatal Network. SA, LC, RER, AN and KY conceptualized the intervention, designed the questionnaire and lecture, and coordinated and supervised data collection. KA, WA and DS assisted with the study implementation and management. $\mathrm{CPH}$ and SRW provided guidance and supervision at every stage. All authors contributed to interpretation of the data, drafting the initial manuscript, critical review and final approval of the manuscript.

\section{Acknowledgements}

This project was supported by the Lebanese Ministry of Education and received funding from the March of Dimes Global Network for Maternal and Infant Health (MOD/GNMIH) Foundation and the Centers for Disease Control and Prevention (CDC).

The authors would like to acknowledge all the pediatricians, obstetricians, midwives, nurses and research assistants who participated in this project and in particular: Dr. Alia Al Aaraj, Ms. Ghadir Abdallah, Dr. Abdallah Adra, Dr. Mona Alameh, Dr. Dany Al Hamod, Dr. David Amaneddine, Dr. Malak Atwi, Ms. Boushra Ayyash, Dr. Maha Dannaoui, Mrs. Bassima Dergham, Mrs.Oula Farhat, Mrs. Faten Fouani, Dr. Labib Ghulmiyyah, Ms. Mirvat Hawari, Dr. Ahmad Malas, Dr. Karim Mroueh, Ms. Mirvat Ouaiza, Dr. Diala Roumani, Mrs. Mira Wehbeh, and Dr. Samar Zawdeh. The authors also thank Ms. Megan Bruno and Ms. Judith Palais of the March of Dimes for their invaluable editorial input.

Note: The content is solely the responsibility of the authors and does not necessarily represent the official views of the March of Dimes /Global Network for Maternal and Infant Health and the Centers for Disease Control and Prevention.

\section{Author details}

${ }^{1}$ the National Collaborative Perinatal Neonatal Network, American University of Beirut Medical Center, Beirut, Lebanon. ${ }^{2}$ American University of Beirut Medical Center, Beirut, Lebanon. ${ }^{3}$ March of Dimes Foundation, White Plains, New York, U.S. ${ }^{4}$ Director General of the Ministry of Public Health of Lebanon, Beirut, Lebanon. ${ }^{5}$ Department of Pediatrics and Adolescent Medicine, American University of Beirut Medical Center, Beirut, Lebanon.

Received: 27 January 2014 Accepted: 27 June 2014

Published: 31 July 2014

\section{References}

1. Centers for Disease Control and Prevention: Achievements in public health, 1900-1999: Family planning. MMWR 1999, 48(47):1073-80.

2. Atrash H, Jack BW, Johnson K: Preconception care: a 2008 update. Curr Opin Obstet Gynecol 2008, 20(6):581-9. doi:10.1097/ GCO.0b013e328317a27c

3. Centers for Disease Control and Prevention: Use of supplements containing folic acid among women of childbearing age-United States, 2007. MMWR Morb Mortal Wkly Rep 2008, 57(01):5-8.

4. Anderson JE, Ebrahim S, Floyd L, Atrash $\mathrm{H}$ : Prevalence of risk factors for adverse pregnancy outcomes during pregnancy and the preconception period-United States, 2002-2004. Matern Child Health J 2006, 10:S101-S106. doi:10.1007/s10995-006-0093-z.
5. U.S. Department of Health and Human Services: Prenatal Care fact sheet. Washington, D.C.: U.S: Department of Health and Human Services, Office on Women's Health; 2009

6. Centers for Disease Control and Prevention: Recommendations to Improve Preconception Health and Health Care-United States: A report of the CDC/ATSDR Preconception Care Work Group and the Select Panel on Preconception Care. MMWR Recomm Rep 2006, 55(No. RR-6):1-23.

7. Atrash H, Jack BW, Johnson K, Coonrod DV, Moos MK, Stubblefield PG, Cefalo R, Damus K, Reddy UM: Where is the "W"oman in MCH? Am J Obstet Gynecol 2008, 199(6 Suppl 2):S259-65. doi:10.1016/j.ajog.2008.08.059.

8. Biermann J, Dunlop AL, Brady C, Dubin C, Brann A Jr: Promising practices in preconception care for women at risk for poor health and pregnancy outcomes. Matern Child Health J 2006, 10:S21-S28. doi:10.1007/s10995-0060097-8.

9. Institute of Medicine of the National Academies: Preterm Birth: Causes, Consequences, and Prevention. Washington, D.C.: Institute of Medicine of The National Academies; 2006.

10. Jack BW, Atrash H, Coonrod DV, Moos MK, O'Donnell J, Johnson K: The clinical content of preconception care: an overview and preparation of this supplement. Am J Obstet Gynecol 2008, 199(6 Suppl 2):S266-79. doi:10.1016/j.ajog.2008.07.067.

11. Korenbrot CC, Steinberg A, Bender C, Newberry S: Preconception care: a systematic review. Matern Child Health J 2002, 6(2):75-88. doi:10.1023/ A:1015460106832.

12. Coonrod DV, Jack BW, Stubblefield PG, Hollier LM, Boggess KA, Cefalo R, Cox SN, Dunlop AL, Hunter KD, Prasad MR, Lu MC, Conry JA, Gibbs RS, Hogan VK: The clinical content of preconception care: infectious diseases in preconception care. Am J Obstet Gynecol 2008, 199(6 Suppl 2):S296-S309. doi:10.1016/j.ajog.2008.08.062.

13. Nasr Hage C, Jalloul M, Sabbah M, Adib SM: Awareness and intake of folic acid for the prevention of neural tube defects among Lebanese women of childbearing age. Matern Child Health J 2012, 16(1):258-65. doi:10.1007/ s10995-010-0736-y.

14. Tamim H, Harrison G, Atoui M, Mumtaz G, El-Kak F, Seoud M, Yunis K: Preconceptional folic acid supplement use in Lebanon. Public Health Nutr 2009, 12(05):687-92. doi:10.1017/S136898000800298X

15. World Health Organization, Center for disease Control and Prevention: Lebanon 2011 (Ages 13-15) Global Youth Tobacco Survey (GYTS) fact sheet. Lebanon: World Health Organization; 2012.

16. Nasreddine L, Naja F, Chamieh M, Adra N, Sibai AM, Hwalla N: Trends in overweight and obesity in Lebanon: evidence from two national cross-sectional surveys (1997 and 2009). BMC Public Health 2012, 12:798. doi:10.1186/1471-2458-12-798.

17. Feig DS, Naylor CD: Eating for two: are guidelines for weight gain during pregnancy too liberal? Lancet 1998, 351(9108):1054-5. doi:10.1016/S01406736(97)06261-2

18. Burdorf A, Figa-Talamanca I, Jensen TK, Thulstrup AM: Effects of occupational exposure on the reproductive system: core evidence and practical implications. Occup Med (Lond) 2006, 56(8):516-20. doi:10.1093/occmed/kql113.

19. Grant SG: Qualitatively and quantitatively similar effects of active and passive maternal tobacco smoke exposure on in utero mutagenesis at the HPRT locus. BMC Pediatr 2005, 5:20. doi:10.1186/ 1471-2431-5-20

20. U.S. Department of Health and Human Services: The health consequences of involuntary exposure to tobacco smoke: A report of the surgeon general. Atlanta: U.S. Department of Health and Human Services, Centers for Disease Control and Prevention, Coordinating Center for Health Promotion, National Center for Chronic Diseases Prevention and Health Promotion, Office on Smoking and Health; 2006

21. Delgado CE: Undergraduate student awareness of issues related to preconception health and pregnancy. Matern Child Health J 2008, 12(6):774-82. doi:10.1007/s10995-007-0300-6.

22. Delgado CE: Pregnancy 101: A Call for Reproductive and Prenatal Health Education in College. Matern Child Health J 2013, 17(2):240-7. doi:10.1007/ s10995-012-0967-1.

23. National Collaborative Perinatal Neonatal Network. [Accessed August 10, 2013]. [Online] Available at: http://www.ncpnn.org.

24. World Health Organization, Lebanese Ministry of Public Health, Lebanese Ministry of Education and Higher Education, Centers for Disease Control and Prevention: Lebanon 2005: Global School-based Student Health Survey. Lebanon: 2007. http://www.who.int/chp/gshs/lebanondataset/en/. 
25. Rao RSP, Lena A, Nair NS, Kamath V, Kamath A: Effectiveness of reproductive health education among rural adolescent girls: a school-based intervention study in Udupi Taluk, Karnataka. Indian. J Med Sci 2008, 62(11):439-43. doi:10.4103/0019-5359.48455.

26. Quillin J, Silberg J, Board P, Pratt L, Bodurtha J: College women's awareness and consumption of folic acid for the prevention of neural tube defects. Genet Med 2000, 2(4):209-213.

27. National Birth Defects Prevention Network: Neural tube defect ascertainment project 2010. [Accessed August 10, 2013]. [Online] Available at: http://www. nbdpn.org/current/resources/ntd_fa_info.html.

28. Charron-Prochownik D, Sereika SM, Wang SL, Hannan MF, Fischl AR, Stewart SH, Dean-McElhinny T: Reproductive health and preconception counseling awareness in adolescents with diabetes: what they don't know can hurt them. Diabetes Educ 2006, 32(2):235-42. doi:10.1177/0145721706286895.

29. Chaaya M, Awwad J, Campbell OMR, Sibai A, Kaddour A: Demographic and Psychosocial Profile of Smoking Among Pregnant Women in Lebanon: Public Health Implications. Matern Child Health J 2003, 7(3):179-86. doi:10.1023/A:1025136421230.

30. Saadé G, Abou Jaoude S, Afifi R, Warren CW, Jones NR: Patterns of tobacco use: Results from the 2005 Global Youth Tobacco Survey in Lebanon. East Mediterr Health J 2008, 14(6):1280-9.

31. Nakkash RT, Khalil J, Chaaya M, Afifi RA: Building research evidence for policy advocacy: a qualitative evaluation of existing smoke-free policies in Lebanon. Asia Pac J Public Health 2010, 22 (3 Suppl):168S-174S. doi:10.1177/1010539510373020.

32. Tobacco Control Research Group: TCRG News. American University of Beirut, Faculty of Health Sciences, Center for Research on Population and Health: Lebanon; 2012. Issue 2.

33. Law No. 174: Tobacco Control and Regulation of Tobacco Products' Manufacturing, Packaging and Advertising. Lebanon: Lebanese parliament, Administration and Justice Committee; 2011.

doi:10.1186/1471-2458-14-774

Cite this article as: Charafeddine et al: Improving awareness of preconception health among adolescents: experience of a school-based intervention in Lebanon. BMC Public Health 2014 14:774.

\section{Submit your next manuscript to BioMed Central and take full advantage of:}

- Convenient online submission

- Thorough peer review

- No space constraints or color figure charges

- Immediate publication on acceptance

- Inclusion in PubMed, CAS, Scopus and Google Scholar

- Research which is freely available for redistribution 